Article

\title{
High-Power DFB Diode Laser-Based CO-QEPAS Sensor: Optimization and Performance
}

\author{
Yufei Ma ${ }^{1, *}$, Yao Tong ${ }^{1}$, Ying He ${ }^{1}$, Xin Yu ${ }^{1}$ and Frank K. Tittel ${ }^{2, *}$ \\ 1 National Key Laboratory of Science and Technology on Tunable Laser, Harbin Institute of Technology, \\ Harbin 150001, China; tongyao9505@163.com (Y.T.); hearkenyi@hit.edu.cn (Y.H.); \\ yuxin0306@hit.edu.cn (X.Y.) \\ 2 Department of Electrical and Computer Engineering, Rice University, 6100 Main Street, \\ Houston, TX 77005, USA \\ * $\quad$ Correspondence: mayufei@hit.edu.cn (Y.M.); fkt@rice.edu (F.K.T.); Tel.: +86-451-8641-3161
}

Received: 12 December 2017; Accepted: 2 January 2018; Published: 4 January 2018

\begin{abstract}
A highly sensitive carbon monoxide (CO) trace gas sensor based on quartz-enhanced photoacoustic spectroscopy (QEPAS) was demonstrated. A high-power distributed feedback (DFB), continuous wave (CW) $2.33 \mu \mathrm{m}$ diode laser with an $8.8 \mathrm{~mW}$ output power was used as the QEPAS excitation source. By optimizing the modulation depth and adding an optimum micro-resonator, compared to a bare quartz tuning fork (QTF), a 10-fold enhancement of the CO-QEPAS signal amplitude was achieved. When water vapor acting as a vibrational transfer catalyst was added to the target gas, the signal was further increased by a factor of $\sim 7$. A minimum detection limit (MDL) of $11.2 \mathrm{ppm}$ and a calculated normalized noise equivalent absorption (NNEA) coefficient of $1.8 \times 10^{-5} \mathrm{~cm}^{-1} \mathrm{~W} / \sqrt{ } \mathrm{Hz}$ were obtained for the reported CO-QEPAS sensor.
\end{abstract}

Keywords: QEPAS; carbon monoxide; high power diode laser; gas sensor

\section{Introduction}

Carbon monoxide (CO) is an air pollutant that is produced by incomplete production combustion activities, such as combustion of natural gas, fossil fuels and other carbon-containing fuels for power generation, petrochemical refining and vehicle or truck transportation. $\mathrm{CO}$ in the atmosphere can react with hydroxyl $(\mathrm{OH})$ to aggravate global warming indirectly [1]. $\mathrm{CO}$ is an important target molecule in hydrocarbon fuel systems, and can be regarded as indicating combustion efficiency [2]. In addition, the presence of $\mathrm{CO}$ in exhaled breath is associated with human diseases at concentration levels of ppm [3-5]. Furthermore, excessive exposure to $\mathrm{CO}$ can cause deprivation of oxygen in human tissue [6]. Therefore, sensitive detection of CO concentration levels has an important significance.

Quartz-enhanced photoacoustic spectroscopy (QEPAS) technique was first reported in 2002 as a modification of conventional photoacoustic spectroscopy [7]. QEPAS eliminates the limitation of a gas cell caused by sound resonance conditions. The quartz tuning fork (QTF) can be placed in the near-field area of the excitation laser beam [8-11]. Therefore, the sealing of the gas is not necessary in this technique, and is only used to separate the gas sample from the surroundings in order to control its pressure. An important feature of a QTF is its low price, small volume, and high quality factor ( $Q$ value $~ 10,000$ at a standard atmospheric pressure) [12-15]. Usually in QEPAS a QTF with resonant frequency $f_{0}$ of $32,768 \mathrm{~Hz}$ acts as an acoustic transducer. Therefore, the corresponding energy accumulation time $\left(\mathrm{t}=\mathrm{Q} / f_{0}\right)$ is $\sim 300 \mathrm{~ms}$ which is significantly longer than any photoacoustic cell used in traditional microphone based photoacoustic spectroscopy. Furthermore, a QTF has very good immunity to ambient noise due to its acoustic quadrupole geometry and a narrow response frequency band $(\sim 4 \mathrm{~Hz})$ [16]. QEPAS has been successfully applied to the detection of numerous trace 
gases [17-23] due to its advantages of high sensitivity, selectivity, and compactness, as well as its fast temporal response.

A QEPAS-based sensor for CO detection employing a $4.6 \mu \mathrm{m}$ quantum cascade laser (QCL) as the excitation source was reported in Refs. [24,25]. Although the strongest absorption line could be targeted and a high excitation power can be achieved when employing a QCL, such CO-QEPAS sensor systems suffer from high cost, high power consumption and size. Compared with QCLs, diode lasers with emission wavelength of $<3 \mu \mathrm{m}$ have several advantages, such as compactness and significantly lower cost. The diode laser can access first overtone absorption band of $\mathrm{CO}$, located at $2.3 \mu \mathrm{m}$, and diode laser-based CO-QEPAS sensors have been reported previously in Refs. [26,27].

The QEPAS signal amplitude $S$ is given by Equation (1) [17]:

$$
S \propto \frac{\alpha P Q}{f_{0}}
$$

where $\alpha$ is the absorption coefficient, $P$ is the optical power, $Q$ is the Q-factor of QTF, $f_{0}$ is the QTF resonance frequency. An important feature of QEPAS is that the performance of QEPAS-based sensors can be improved when the excitation laser power is increased [28], since QEPAS detection sensitivity scales linearly with excitation laser power $P$ (see Equation (1)). However, to date, commercially available $2.3 \mu \mathrm{m}$ diode lasers have a maximum output power of $\sim 2 \mathrm{~mW}$, which limits the CO-QEPAS sensor performance.

In this paper, a sensitive QEPAS-based CO trace gas sensor was demonstrated. A high-power distributed feedback (DFB) diode laser with a fiber pigtail output power of $\sim 9 \mathrm{~mW}$ was used as the excitation source. The laser wavelength modulation depth and the length of micro-resonator were optimized. Furthermore, enhancement of the CO-QEPAS signal was realized by the addition of water vapor to improve the $\mathrm{CO}$ vibrational-translational relaxation rate.

\section{Experiment Setup}

A schematic of the QEPAS-based CO sensor platform is shown in Figure 1. As an excitation source, a $2.3 \mu \mathrm{m}$ fiber-coupled, DFB, continuous-wave (CW) diode laser (Model \#: KELD1G5BAAH, NEL Corp., Kawasaki City, Japan) in a 14-pin butterfly package that included a thermoelectric controller (TEC) operating at $19^{\circ} \mathrm{C}$ was employed. The current of the DFB-CW diode laser was modulated at half the resonance frequency $\left(f=f_{0} / 2 \approx 16.3 \mathrm{kHz}\right)$ of the QTF. The laser beam was collimated and focused between the QTF prongs by using a fiber collimation package (focal length: $11 \mathrm{~mm}$, Model \#: F021APC-2000, Thorlabs, Newton, NJ, USA) and a plano-convex lens (L) with a focal length of $40 \mathrm{~mm}$. A transimpedance amplifier (TA) with a resistance of $10 \mathrm{M} \Omega$ was used to convert the piezoelectric current to voltage. The voltage signal was used to demodulate the second harmonics $(2 f)$ signal. Two stainless steel tubes formed an acoustic micro-resonator (MR), which improved the detection sensitivity of the QEPAS system. The sensor system was processed by a laptop computer (PC) using LabVIEW software.

From Figure 2, we can see that the maximum optical power emitted by the $2.3 \mu \mathrm{m}$ fiber-coupled, DFB-CW diode laser operating at a temperature of $19^{\circ} \mathrm{C}$ and an injection current of $300 \mathrm{~mA}$ was $\sim 8.8 \mathrm{~mW}$.

The $200 \mathrm{ppb}$ CO absorption lines in the $2.3 \mu \mathrm{m}$ first-overtone absorption band at a temperature of $296 \mathrm{~K}$ and a standard atmospheric pressure, according to the HITRAN 2012 database [29], are shown in Figure 3. This simulation shows that a line located at $2330.19 \mathrm{~nm}\left(4291.50 \mathrm{~cm}^{-1}\right)$ with an absorbance coefficient of $8.85 \times 10^{-8} \mathrm{~cm}^{-1}$ is one of the strongest lines, at $\sim 2.3 \mu \mathrm{m}$. The DFB-CW diode laser wavelength can be tuned to cover this absorption line by changing the laser injection current at a constant TEC temperature of $19{ }^{\circ} \mathrm{C}$. 


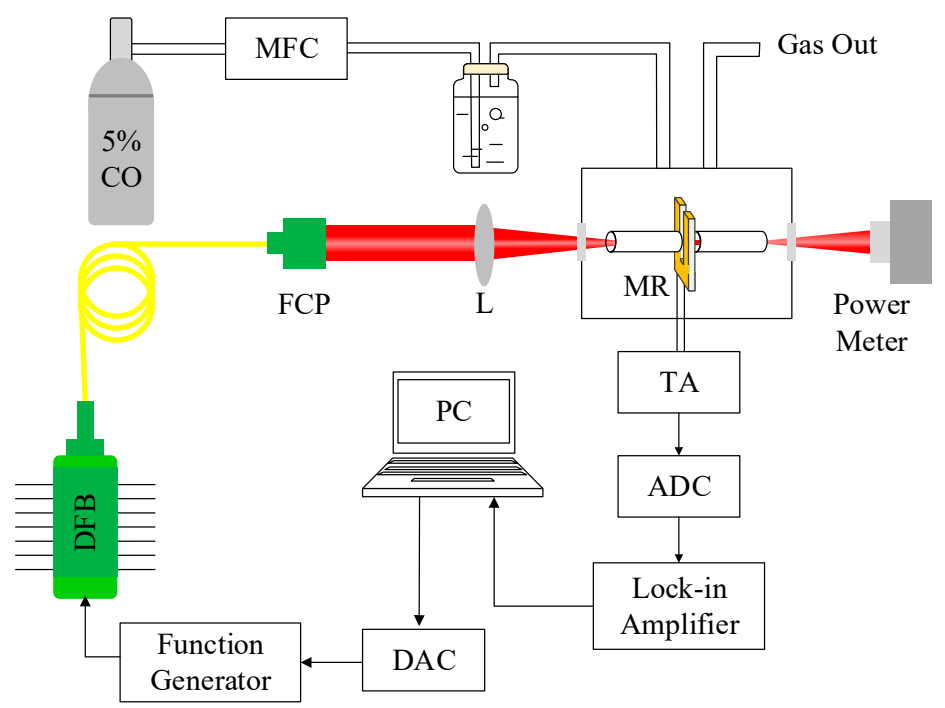

Figure 1. Schematic of a high-power DFB, CW diode laser-based CO-QEPAS sensor platform.

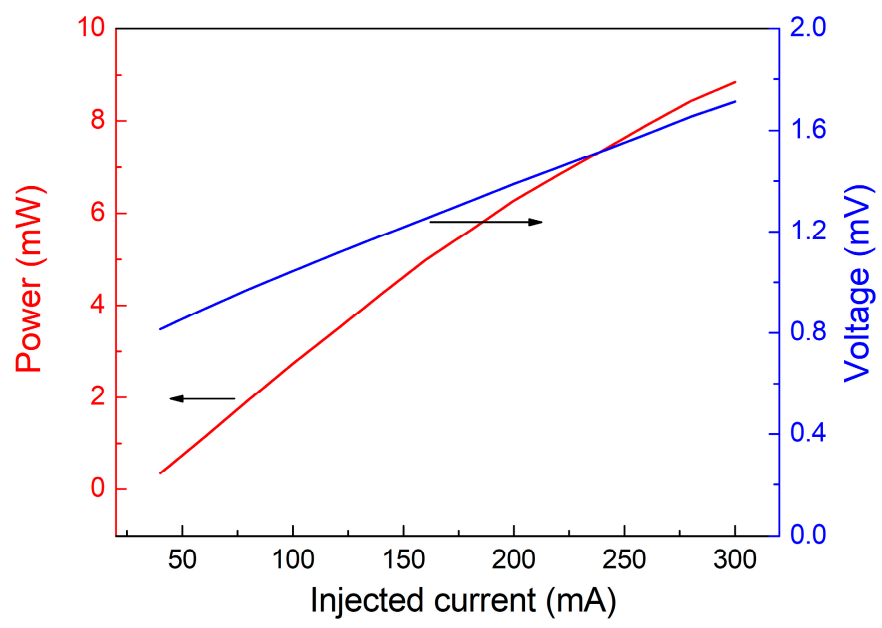

Figure 2. $2.3 \mu \mathrm{m}$ diode laser output performance.

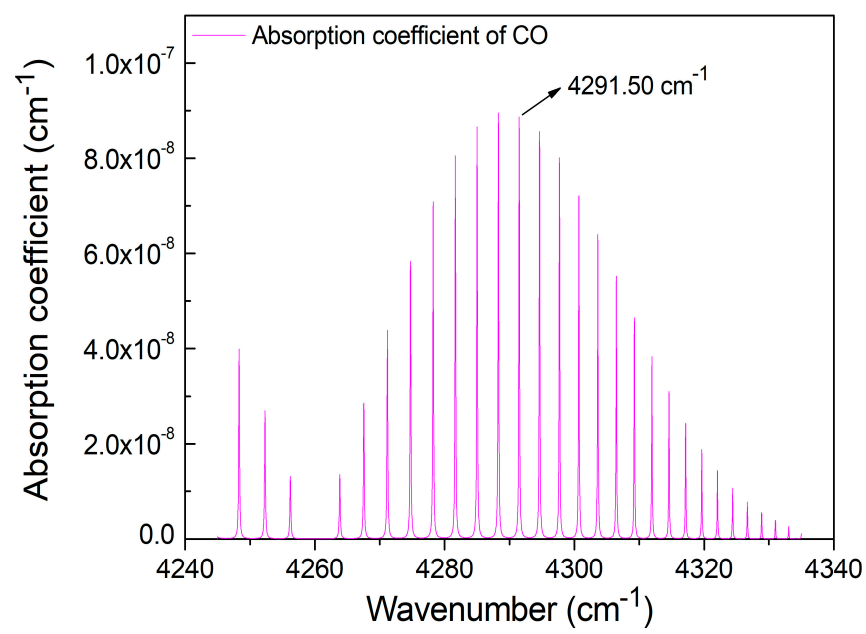

Figure 3. Absorption lines for $\mathrm{CO}$ molecules in the $2.3 \mu \mathrm{m}$ first overtone absorption band based on the HITRAN 2012 database. 


\section{Results and Discussion}

The QEPAS sensor performance can be significantly improved when an acoustic micro-resonator (MR) is added. There are two main kinds of micro-resonators, an on-beam and an off-beam MR [30-32]. Compared to an off-beam configuration, the on-beam has the advantage of a stronger acoustic coupling efficiency. Therefore, in this research, an on-beam architecture was chosen. The optimal length of MR range is $\lambda_{s} / 4 \sim \lambda_{s} / 2$, where $\lambda_{s}$ is the sound wavelength. The calculated optimal length of the MR is $2.6 \sim 5.2 \mathrm{~mm}$, based on the speed of sound, which is $340 \mathrm{~m} / \mathrm{s}$ in $5 \% \mathrm{CO}: \mathrm{N}_{2}$. In this experiment, the lengths of the stainless tubes were $3 \mathrm{~mm}, 4 \mathrm{~mm}, 5 \mathrm{~mm}$ or $5.5 \mathrm{~mm}$. The inner diameter of the stainless tubes was $0.5 \mathrm{~mm}$, and the gap between the QTF and MR tubes was $25 \mu \mathrm{m}$. The optimal distance from QTF tips to the axis of MR was chosen to be $0.7 \mathrm{~mm}$ [11].

Figure 4 shows the QEPAS signal amplitude as a function of laser wavelength modulation depth for 4 different MRs for a 5\% CO: $\mathrm{N}_{2}$ gas mixture. The QEPAS signal amplitude increased with the modulation depth. However, when the modulation depth was $>0.38 \mathrm{~cm}^{-1}$, the signal amplitude did not change. It can be seen that the CO-QEPAS signal improved when the MRs were added. A maximum signal enhancement of 10 times was obtained when a MR with a length ( $\left.\mathrm{L}_{\mathrm{MR}}\right)$ of $5 \mathrm{~mm}$ was used. For this condition, the QEPAS system had the strongest acoustic coupling. The measured $2 f$ QEPAS signal with a modulation depth of $0.38 \mathrm{~cm}^{-1}$ and $\mathrm{L}_{\mathrm{MR}}=5 \mathrm{~mm}$ is depicted in Figure 5 .

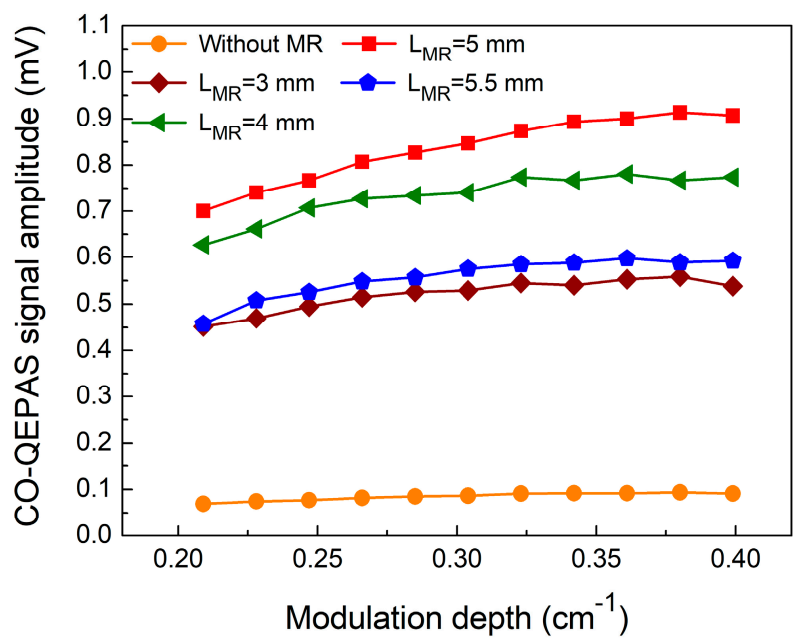

Figure 4. CO-QEPAS signal amplitude as a function of modulation depth.

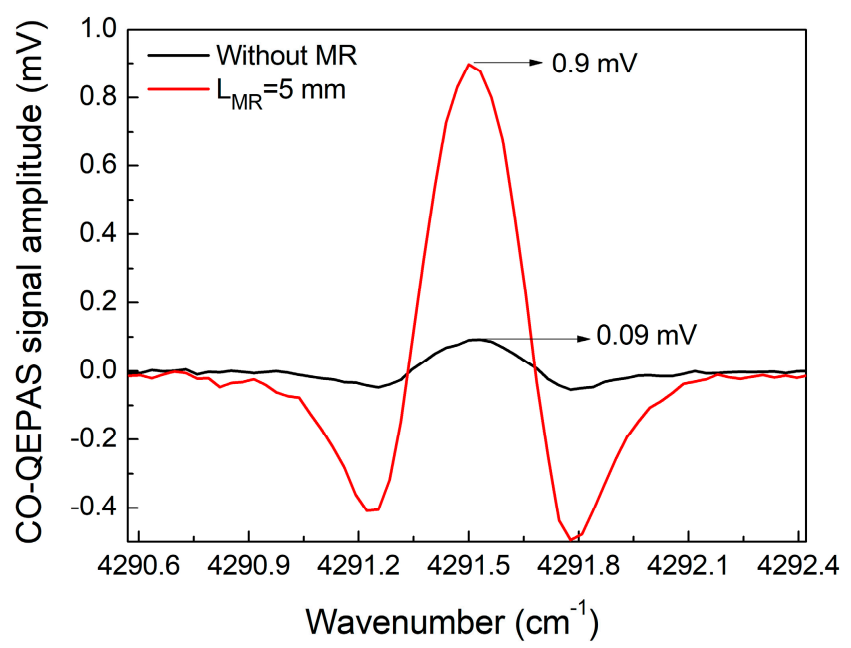

Figure 5. QEPAS signal amplitude without $M R$ and $M R$ with a length $\left(L_{M R}\right)=5 \mathrm{~mm}$. 
Enhancement of the CO-QEPAS signal was realized by the addition of water vapor to improve the $\mathrm{CO}$ vibrational-translational relaxation rates. The addition of water vapor with a concentration of $1.01 \%$ in the gas mixture resulted in a signal improvement of $\sim 7$ fold, as shown in Figure 6 a. This confirmed that water vapor is an efficient catalyst for the vibrational-relaxation energy reactions in the gas phase. Figure $6 \mathrm{~b}$ depicts the background signal measured when the QEPAS sensor cell was flushed with high-purity nitrogen $\left(\mathrm{N}_{2}\right)$. The $1 \sigma$ background signal was $1.4 \mu \mathrm{V}$. QEPAS background noise is limited by the fundamental Johnson thermal noise of the QTF. Based on the data depicted in Figure 6, the minimum detection limit (MDL) was $11.2 \mathrm{ppm}$ for a $1 \mathrm{sec}$ time constant of the lock-in amplifier, which is significantly better than 43.3 ppm, as reported in Ref. [27]. The calculated normalized noise equivalent absorption (NNEA) coefficient for the reported CO-QEPAS sensor was $1.8 \times 10^{-5} \mathrm{~cm}^{-1} \mathrm{~W} / \sqrt{ } \mathrm{Hz}$.

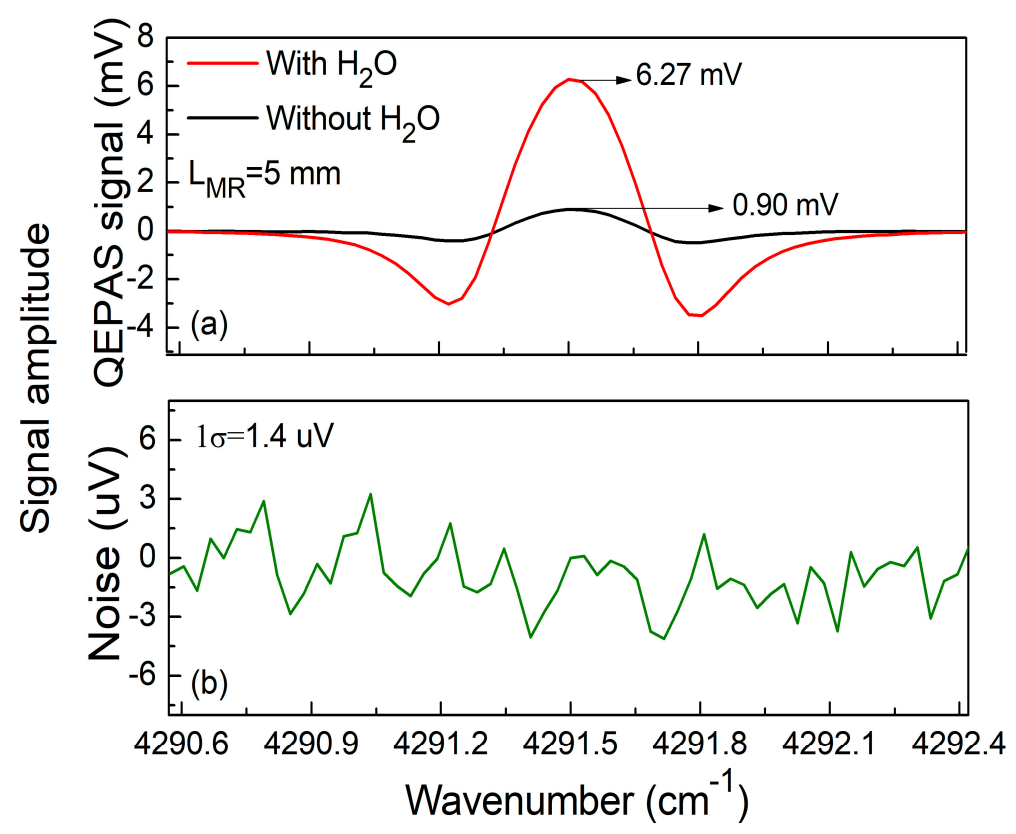

Figure 6. Signal amplitude. (a) QEPAS signal based on a $5 \mathrm{~mm} \mathrm{MR}$ with and without $\mathrm{H}_{2} \mathrm{O}$; (b) Pure $\mathrm{N}_{2}$ for a noise background determination.

The above measurements were carried out at room temperature (296 K) and atmospheric pressure (1 atm). Wavelength modulation spectroscopy (WMS) with 2nd harmonic detection was utilized for concentration measurements $[33,34]$ in this paper. The absorption coefficient in WMS can be expanded into a Fourier series. $H_{n}(v)$ is the nth Fourier component of the modulated absorption coefficient, and is expressed as Equation (2) [35]:

$$
H_{n}\left(v_{0}, v_{a}\right)=\frac{2^{1-n} I_{0} L}{n !} v_{a}^{n}\left[\frac{d^{n} \alpha(v)}{d v^{n}}\right]_{v=v_{0}}=\frac{2^{1-n} I_{0} N L S(T)}{n !} v_{a}^{n}\left[\frac{d^{n} g(v)}{d v^{n}}\right]_{v=v_{0}}, n \geq 1
$$

where $I_{0}$ is the laser intensity, $N$ is the molecular density, $L$ is the absorption pass length, $S(T)$ is the absorption line intensity, $g(v)$ is the line shape function.

$$
P_{2 f} \propto H_{2}\left(v_{0}, v_{a}\right)=\frac{2^{-1} I_{0} N L S(T)}{n !} v_{a}^{2}\left[\frac{d^{2} g_{\mathrm{V}}(v)}{d v^{2}}\right]_{v=v_{0}}
$$

The second harmonic acoustic signal $\mathrm{P}_{2 f}$ of QEPAS is proportional to $H_{2}(v)$, as shown in Equation (3). The $2 f$ signal intensities at different temperatures and pressures were calculated according to the above equation, and are shown in Figure 7. The temperature sensitivity and pressure sensitivity for the concentration retrieval were calculated based on the derivation of $2 f$ signal, and are also 
depicted in Figure 7a,b. It can be seen that the temperature sensitivity and pressure sensitivity are $0.15 \mathrm{ppm} / \mathrm{K}$ and $0.67 \mathrm{ppm} / \mathrm{atm}$, respectively, at $296 \mathrm{~K}$ and $1 \mathrm{~atm}$, which means that, under the laboratory conditions, the CO-QEPAS sensor was not insensitive to the environmental variables.
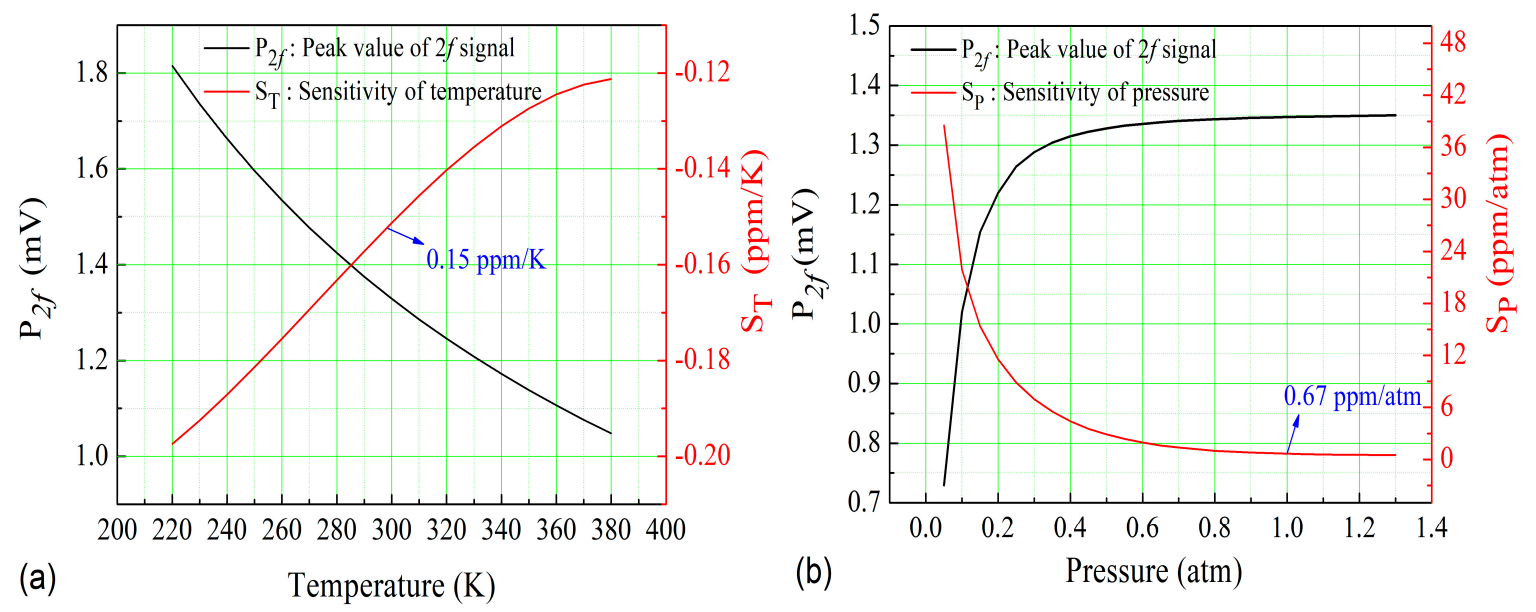

Figure 7. (a) $2 f$ signal intensity and temperature sensitivity at different temperatures; (b) $2 f$ signal intensity and pressure sensitivity at different pressures.

\section{Conclusions}

In conclusion, a sensitive CO-QEPAS sensor based on a high-power DFB-CW diode laser was demonstrated. Due to the fact that QEPAS detection sensitivity scales linearly with excitation laser power, the $8.8 \mathrm{~mW}$ diode laser output power was advantageous for improving sensor performance. The laser wavelength modulation depth was optimized. Different micro-resonators with lengths of $3 \mathrm{~mm}, 4 \mathrm{~mm}, 5 \mathrm{~mm}$ and $5.5 \mathrm{~mm}$ were added to both sides of the QTF to form an acoustic resonant cavity to improve the signal amplitude. Further enhancement of the CO-QEPAS signal was realized by the addition of water vapor with a $1.01 \%$ concentration to improve the $\mathrm{CO}$ vibrational-translational relaxation rates. Finally, an excellent MDL of $11.2 \mathrm{ppm}$ and a calculated normalized noise equivalent absorption (NNEA) coefficient of $1.8 \times 10^{-5} \mathrm{~cm}^{-1} \mathrm{~W} / \sqrt{ } \mathrm{Hz}$ were obtained. With a CO detection sensitivity of $10 \mathrm{ppm}$ concentration levels, the reported CO-QEPAS-based sensor is suitable for applications in environmental monitoring, combustion science and other applications.

Acknowledgments: This work was supported by the National Natural Science Foundation of China (Grant No. 61505041), the Natural Science Foundation of Heilongjiang Province of China (Grant No. F2015011), the Financial Grant from the China Postdoctoral Science Foundation (Grant No. 2014M560262 and 2015T80350), the Financial Grant from the Heilongjiang Province Postdoctoral Foundation (Grant No. LBH-Z14074 and LBH-TZ0602), the Fundamental Research Funds for the Central Universities and the Application Technology Research and Development Projects of Harbin (No. 2016RAQXJ140). Frank K. Tittel acknowledges support from National Science Foundation (NSF) ERC MIRTHE award and Robert Welch Foundation (No. C-4925U).

Author Contributions: Yufei Ma was the group leader and was in charge of experiments. Yao Tong performed the reported experiments, data analysis and preparation of this manuscript. Ying He and Xin Yu were involved in discussions. Frank K. Tittel provided valuable guidance for the experiments, as well as in the preparation of the manuscript. All authors were involved in numerous discussions related in all aspects of this paper.

Conflicts of Interest: The authors declare no conflict of interest.

\section{References}

1. Khalil, M.A.; Rasmussen, R.A. Carbon Monoxide in the earth's atmosphere: Increasing trend. Science 1984, 224, 54-56. [CrossRef] [PubMed]

2. Farooq, A.; Jeffries, J.B.; Hanson, R.K. $\mathrm{CO}_{2}$ concentration and temperature sensor for combustion gases using diode-laser absorption near $2.7 \mu \mathrm{m}$. Appl. Phys. B 2008, 90, 619-628. [CrossRef] 
3. Zayasu, J.; Sekizawa, K.; Okinaga, S.; Yamaya, M.; Ohrui, A.; Sasaki, H. Increased carbon monoxide in exhaled air of asthmatic patients. Am. J. Respir. Crit. Care 1997, 156, 1140-1143. [CrossRef] [PubMed]

4. Paredi, P.; Biernacki, W.; Invernizzi, G.; Kharitonov, S.A.; Barnes, P.J. Exhaled carbon monoxide levels elevated in diabetes and correlated with glucose concentration in blood: A new test for monitoring the disease? Chest 1999, 116, 1007-1011. [CrossRef] [PubMed]

5. Okuyama, H.; Yonetani, M.; Uetani, Y.; Nakamura, H. End-tidal carbon monoxide is predictive for neonatal non-hemolytic hyperbilirubinemia. Pediatr. Int. 2001, 43, 329-333. [CrossRef] [PubMed]

6. Ernst, A.; Zibrak, J.D. Carbon monoxide poisoning. N. Engl. J. Med. 1998, 339, 1603-1608. [CrossRef] [PubMed]

7. Kosterev, A.A.; Bakhirkin, Y.A.; Curl, R.F.; Tittel, F.K. Quartz-enhanced photoacoustic spectroscopy. Opt. Lett. 2002, 27, 1902-1904. [CrossRef] [PubMed]

8. Helman, M.; Moser, H.; Dudkowiak, A.; Lendl, B. Off-beam quartz-enhanced photoacoustic spectroscopy-based sensor for hydrogen sulfide trace gas detection using a mode-hop-free external cavity quantum cascade laser. Appl. Phys. B 2017, 123, 141. [CrossRef]

9. Borri, S.; Patimisco, P.; Galli, I.; Mazzotti, D.; Giusfredi, G.; Akikusa, N.; Yamanishi, M.; Scamarcio, G.; de Natale, P.; Spagnolo, V. Intracavity quartz-enhanced photoacoustic sensor. Appl. Phys. Lett. 2014, 104, 091114. [CrossRef]

10. Dong, Y.J.; Chen, J.; Luo, L.Q.; Forsberg, E.; He, S.L.; Yan, C.S. Modeling and implementation of a fiber-based quartz-enhanced photoacoustic spectroscopy system. Appl. Opt. 2015, 54, 4202-4206. [CrossRef]

11. Ma, Y.F.; He, Y.; Yu, X.; Zhang, J.B.; Sun, R.; Tittel, F.K. Compact all-fiber quartz-enhanced photoacoustic spectroscopy sensor with a $30.72 \mathrm{kHz}$ quartz tuning fork and spatially resolved trace gas detection. Appl. Phys. Lett. 2016, 108, 091115. [CrossRef]

12. Starecki, T.; Wieczorek, P.Z. A high sensitivity preamplifier for quartz tuning forks in QEPAS (quartz enhanced photoacoustic spectroscopy) applications. Sensors 2017, 17, 2528. [CrossRef] [PubMed]

13. Mordmüller, M.; Köhring, M.; Schade, W.; Willer, U. An electrically and optically cooperated QEPAS device for highly integrated gas sensors. Appl. Phys. B 2015, 119, 111-118. [CrossRef]

14. Mordmueller, M.; Schade, W.; Willer, U. QEPAS with electrical co-excitation for photoacoustic measurements in fluctuating background gases. Appl. Phys. B 2017, 123, 224. [CrossRef]

15. Ma, Y.F.; Yu, X.; Yu, G.; Li, X.D.; Zhang, J.B.; Chen, D.Y.; Sun, R.; Tittel, F.K. Multi-quartz-enhanced photoacoustic spectroscopy. Appl. Phys. Lett. 2015, 107, 021106. [CrossRef]

16. Aoust, G.; Levy, R.; Raybaut, M.; Godard, A.; Melkonian, J.M.; Lefebvre, M. Theoretical analysis of a resonant quartz-enhanced photoacoustic spectroscopy sensor. Appl. Phys. B 2017, 123, 63. [CrossRef]

17. Ma, Y.F.; He, Y.; Yu, X.; Chen, C.; Sun, R.; Tittel, F.K. HCl ppb-level detection based on QEPAS sensor using a low resonance frequency quartz tuning fork. Sens. Actuators B 2016, 233, 388-393. [CrossRef]

18. Waclawek, J.; Moser, H.; Lendl, B. Compact quantum cascade laser based quartz-enhanced photoacoustic spectroscopy sensor system for detection of carbon disulfide. Opt. Express 2016, 24, 6559-6571. [CrossRef] [PubMed]

19. Wang, Z.; Li, Z.; Ren, W. Quartz-enhanced photoacoustic detection of ethylene using a $10.5 \mu \mathrm{m}$ quantum cascade laser. Opt. Express 2016, 24, 4143-4154. [CrossRef] [PubMed]

20. Yi, H.M.; Maamary, R.; Gao, X.M.; Sigrist, M.W.; Fertein, E.; Chen, W.D. Short-lived species detection of nitrous acid by external-cavity quantum cascade laser based quartz-enhanced photoacoustic absorption spectroscopy. Appl. Phys. Lett. 2015, 106, 101109. [CrossRef]

21. Liu, K.; Zhao, W.X.; Wang, L.; Tan, T.; Wang, G.S.; Zhang, W.J.; Gao, X.M.; Chen, W.D. Quartz-enhanced photoacoustic spectroscopy of HCN from 6433 to $6613 \mathrm{~cm}^{-1}$. Opt. Commun. 2015, 340, 126-130. [CrossRef]

22. Triki, M.; Nguyen Ba, T.; Vicet, A. Compact sensor for methane detection in the mid infrared region based on quartz enhanced photoacoustic spectroscopy. Infrared Phys. Technol. 2015, 69, 74-80. [CrossRef]

23. He, Y.; Ma, Y.F.; Tong, Y.; Yu, X.; Peng, Z.F.; Gao, J.; Tittel, F.K. Long distance, distributed gas sensing based on micro-nano fiber evanescent wave quartz-enhanced photoacoustic spectroscopy. Appl. Phys. Lett. 2017, 111, 241102. [CrossRef]

24. Dong, L.; Lewicki, R.; Liu, K.; Buerki, P.R.; Weida, M.J.; Tittel, F.K. Ultra-sensitive carbon monoxide detection by using EC-QCL based quartz-enhanced photoacoustic spectroscopy. Appl. Phys. B 2012, 107, 275-283. [CrossRef] 
25. Ma, Y.F.; Lewicki, R.; Razeghi, M.; Tittel, F.K. QEPAS based ppb-level detection of $\mathrm{CO}$ and $\mathrm{N}_{2} \mathrm{O}$ using a high power CW DFB-QCL. Opt. Express 2013, 21, 1008-1019. [CrossRef] [PubMed]

26. Dong, L.; Kosterev, A.A.; Thomazy, D.; Tittel, F.K. Compact portable QEPAS multi-gas sensor. Proc. SPIE 2011, 7945, 631-640.

27. Ma, Y.F.; Yu, G.; Zhang, J.B.; Yu, X.; Sun, R. Sensitive detection of carbon monoxide based on a QEPAS sensor with a $2.3 \mu \mathrm{m}$ fiber-coupled antimonide diode laser. J. Opt. 2015, 17, 055401. [CrossRef]

28. Ma, Y.F.; He, Y.; Zhang, L.G.; Yu, X.; Zhang, J.B.; Sun, R.; Tittel, F.K. Ultra-high sensitive acetylene detection using quartz-enhanced photoacoustic spectroscopy with a fiber amplified diode laser and a $30.72 \mathrm{kHz}$ quartz tuning fork. Appl. Phys. Lett. 2017, 110, 031107. [CrossRef]

29. Rothman, L.S.; Gordon, I.E.; Babikov, Y.; Barbe, A.; ChrisBenner, D.; Bernath, P.F.; Birk, M.; Bizzocchi, L.; Boudon, V.; Brown, L.R.; et al. The HITRAN 2012 molecular spectroscopic database. J. Quant. Spectrosc. Radiat. 2013, 130, 4-50. [CrossRef]

30. Gong, P.; Xie, L.; Qi, X.Q.; Wang, R.; Wang, H.; Chang, M.C.; Yang, H.X.; Sun, F.; Li, G.P. A quartz-enhanced photoacoustic spectroscopy sensor for measurement of water vapor concentration in the air. Chin. Phys. B 2015, 24, 282-286. [CrossRef]

31. Liu, K.; Guo, X.Y.; Yi, H.M.; Chen, W.D.; Zhang, W.J.; Gao, X.M. Off-beam quartz-enhanced photoacoustic spectroscopy. Opt. Lett. 2009, 34, 1594-1596. [CrossRef] [PubMed]

32. Jiang, M.; Feng, Q.L.; Wang, C.Y.; Wei, Y.F.; Liang, T.L.; Wang, X.F. Ammonia sensor based on QEPAS with HC-PBF as reference cell. Proc. SPIE 2015, 9620, 96200F. [CrossRef]

33. Schilt, S.; Thévenaz, L. Wavelength modulation photoacoustic spectroscopy: Theoretical description and experimental results. Infrared Phys. Technol. 2006, 48, 154-162. [CrossRef]

34. Ma, Y.F.; He, Y.; Tong, Y.; Yu, X.; Tittel, F.K. Ppb-level detection of ammonia based on QEPAS using a power amplified laser and a low resonance frequency quartz tuning fork. Opt. Express 2017, 25, 29356-29364. [CrossRef]

35. Reid, J.; Labrie, D. Second-Harmonic Detection with tunable diode lasers-comparison of experiment and theory. Appl. Phys. B 1981, 26, 203-210. [CrossRef]

(C) 2018 by the authors. Licensee MDPI, Basel, Switzerland. This article is an open access article distributed under the terms and conditions of the Creative Commons Attribution (CC BY) license (http:/ / creativecommons.org/licenses/by/4.0/). 